\title{
Article \\ Stray Dogs and Public Health: Population Estimation in Punjab, India
}

\author{
Gurlal S. Gill ${ }^{1,2}$, Balbir B. Singh ${ }^{1,3, *}$, Navneet K. Dhand ${ }^{3}\left(\mathbb{D}\right.$, Rabinder S. Aulakh $^{1}$, Michael P. Ward ${ }^{3}(\mathbb{C}$ \\ and Victoria J. Brookes ${ }^{3}(\mathbb{B}$ \\ 1 Centre for One Health, Guru Angad Dev Veterinary and Animal Sciences University (GADVASU), \\ Ludhiana 141001, India; gillkangar@pau.edu (G.S.G.); rsaulakh@gadvasu.in (R.S.A.) \\ 2 Krishi Vigyan Kendra, Faridkot, 151203, Punjab Agricultural University, Ludhiana 141004, India \\ 3 Sydney School of Veterinary Science, The University of Sydney, Camperdown, NSW 2006, Australia; \\ navneet.dhand@sydney.edu.au (N.K.D.); michael.ward@sydney.edu.au (M.P.W.); \\ victoria.brookes@sydney.edu.au (V.J.B.) \\ * Correspondence: balbir.dhaliwal@sydney.edu.au
}

Citation: Gill, G.S.; Singh, B.B.; Dhand, N.K.; Aulakh, R.S.; Ward, M.P.; Brookes, V.J. Stray Dogs and Public Health: Population Estimation in Punjab, India. Vet. Sci. 2022, 9, 75. https://doi.org/10.3390/ vetsci9020075

Academic Editor: Valentina Virginia Ebani

Received: 7 January 2022

Accepted: 3 February 2022

Published: 10 February 2022

Publisher's Note: MDPI stays neutral with regard to jurisdictional claims in published maps and institutional affiliations.

Copyright: (C) 2022 by the authors. Licensee MDPI, Basel, Switzerland. This article is an open access article distributed under the terms and conditions of the Creative Commons Attribution (CC BY) license (https:// creativecommons.org/licenses/by/ $4.0 /)$.

\begin{abstract}
The overpopulation of stray dogs is a serious public health and animal welfare concern in India. Neglected zoonotic diseases such as rabies and echinococcosis are transmitted at the stray-dog human interface, particularly in low to middle-income countries. The current study was designed to estimate the stray dog populations in Punjab to enhance the implementation of animal birth and disease (for example, rabies vaccination) control programs. This is the first systematic estimation of the stray dog population using a recommended method (mark-re-sight) in Punjab, India. The study was conducted from August 2016 to November 2017 in selected villages or wards in Punjab. For the rural areas, 22 sub-districts in each district were randomly selected, then one village from each of the 22 selected sub-districts was selected (by convenience sampling). For urban areas, 3 towns (less than 100,000 human population) and 2 large cities (more than or equal to 100,000 human population) were randomly selected, followed by convenience selection of two wards from each of the 5 selected towns/cities. To estimate the dog population size, we used a modified mark-re-sight procedure and analysed counts using two methods; the Lincoln-Petersen formula with Chapman's correction, and an application of Good-Turing theory (SuperDuplicates method; estimated per $\mathrm{km}^{2}$ and per 1000 adult humans and were compared between localities (villages vs. towns), dog sex (male vs. female) and age group (young vs. adult) using linear mixed models with district as a random effect. The predicted mean $(95 \% \mathrm{CI})$ count of the dogs per village or ward were extrapolated to estimate the number of stray dogs in Punjab based on (a) the number of villages and wards in the state; (b) the adult human population of the state and (c) the built-up area of the state. Median stray dog populations per village and per ward using the Lincoln-Petersen formula with Chapman's correction were estimated to be 33 and 65 dogs, respectively. Higher estimates of 61 per village and 112 per ward are reported using the SuperDuplicates method. The number of males was significantly higher than the number of females and the number of adult dogs was about three times the number of young dogs. Based on different methods, estimates of the mean stray dog population in the state of Punjab ranged from 519,000 to 1,569,000. The current study revealed that there are a substantial number of stray dogs and a high number reside in rural (versus urban) areas in Punjab. The estimated stray dog numbers pose a potential public health hazard in Punjab. This impact requires assessment. The estimated stray dog numbers will help develop a dog population and rabies control program in which information about the logistics required as well as costs of implementing such programmes in Punjab can be incorporated.
\end{abstract}

Keywords: India; Punjab; roaming-dog; stray dog count; public health 


\section{Introduction}

Dogs are the first species to have been domesticated and share a close cultural, social and economic association with humans [1]. Pets are treated as family members in the Western world and approximately $50 \%$ of households keep pets [2]. Domestication of dogs has been shown to provide many benefits to humans [3]. For example, pet ownership is associated with a decreased prevalence of depressive symptoms [4]. It has been reported that pet owners visit their doctor less often, use fewer medications and have lower blood pressure and cholesterol levels than non-pet owners [5]. Dogs have roles in the management of many psychological, psychiatric and biomedical conditions in humans [6,7]. However, dog domestication - in particular, the overpopulation of stray dogs—can have negative impacts on public health and animal welfare.

A stray dog is defined as any dog in a public area that is not under direct human control. Therefore, this term encompasses unowned and community-owned dogs but excludes dogs on leashes or under direct human control at the time of a survey (WSPA, 2009). Stray dogs can be either previously owned dogs [8,9] or can be feral dogs (wild dogs) that have never been owned [10]. Factors such as easy availability of food, lack of predators, low number of competitors, and the ease with which a breeding partner can be found can lead to rapid increases in stray dog populations [11].

In contrast to the health benefits provided by pet dogs, stray dogs contribute to environmental pollution, dog bite incidence and can act as reservoirs of many important zoonotic parasites (for example, Toxocara, Ancylostoma and Echinococcus) via faecal contamination of soil and water [12-14], and infectious diseases (for example, rabies, salmonellosis). The faecal shedding of pathogens by stray dogs contaminates the environment [15], which is of substantial public and animal health concern. Stray dogs also contribute to incidents such as bites and accidents and damage wildlife populations [16-19]. In addition, stray dogs have a substantial negative economic impact at tourist destinations [20].

The overpopulation of stray dogs is an important animal welfare and public health concern in India [21,22]. It has been reported that $92-97 \%$ of human rabies deaths occur in India following bites from infected dogs, of which $60 \%$ have been reported from stray dogs [23,24]. Stray dogs transmit many important zoonotic pathogens in India [25]. Large numbers of dogs have been reported to roam the streets in many parts of the country [26-28]. These high numbers of stray dogs are due to large amounts of edible waste available on the streets, cultural tolerance of stray dogs and a lack of consistently employed sustained birth control programs [29].

Mass culling of dog populations was historically used to control rabies in India [30], but this has been replaced by animal birth control (ABC) programs under the Prevention of Cruelty to Animals Act, 1960 and the Animal Birth Control Rules, 2001 (http:/ / envfor.nic. in/legis/awbi/awbi13.pdf, accessed on 15 March 2019). Within an ABC program, street dogs are sterilized, vaccinated for rabies and subsequently released into the same area from which they were captured. The ABC program has been implemented in small areas in India with effective results [26,30-32]. For example, a decline in human dog-bite cases and stray dog numbers in Jaipur, India, during and after the implementation of the $A B C$ program $[27,31]$ has been reported.

According to official data, there are 17.14 million stray dogs in India [33]. This estimate is based on the collection and compilation of information from veterinary personnel based on their areas of work, and passive surveillance. Reliable and repeatable scientific methods have not been used to derive this estimate, and so it might be inaccurate and likely lacks precision.

Globally, recommended methods for the estimation of the size of stray dog populations include total or direct counts, and mark-resight or capture-recapture methods [34,35]. However, total or direct counts are not practical over large geographical areas and dog populations [34,35]. In the past, several capture-recapture enumeration methods have been used to drive free-roaming dog population estimates [36]. Out of these, Lincoln-Petersen's formula with Chapman's correction have been commonly used to drive these estimates. 
Recent studies indicate the usefulness of the SuperDuplicates method to estimate dog counts, particularly for two sample surveys conducted on consecutive days [36].

Stray dog population estimates using the recommended methods have been carried out in countries neighbouring India such as Bangladesh [37,38] and Bhutan [38], as well as in other parts of the country such as Rajasthan [27] and Maharashtra [28], but not in the Punjab state of India. Additionally, stray dog age- and gender-specific data necessary to facilitate $A B C$ programs are not available from the official estimates. Therefore, the current study was planned to estimate the stray dog population size in Punjab, India. Demographic data - as well as some health indices (lameness, skin conditions, and open wounds) - were also recorded.

\section{Methods}

\subsection{Study Area}

The study was conducted in Punjab State in the northwest region of India (latitudes $29.30^{\circ}$ North to $32.32^{\circ}$ North and longitudes $73.55^{\circ}$ East to $76.50^{\circ}$ East) between August 2016 and November 2017 (16 months). Punjab has a land area of 50,362 km² comprising $48,265 \mathrm{~km}^{2}$ rural and $2097 \mathrm{~km}^{2}$ urban areas, including 237 towns and cities (http:/ / punjab.gov.in/know-punjab, accessed 15 March 2019). Punjab has a human population of $27,743,338$ with a density of 551 people $/ \mathrm{km}^{2}$.

\subsection{Selection of Villages and Wards}

The state has 22 districts divided into 81 tehsils (sub-districts), containing 12,581 villages and 217 towns and cities. Of the towns and cities, 18 have >100,000 humans and 199 have $<100,000$ humans (http:/ / www.citypopulation.de/php/india-punjab.php, accessed on 15 March 2019). For village selection from the rural areas, 22 sub-districts (one from each district) were randomly selected, followed by convenience selection of one village from each of the selected sub-districts (i.e., a total of 22 villages). For municipal ward selection from the urban areas, 3 towns (with $<100,000$ humans) and 2 large cities (with $>100,000$ humans) were randomly selected followed by convenience selection of two wards each from the selected towns and cities (a total of 10 wards). The official adult human population data were collected from the respective village heads or municipal councillors (Supplementary Table S1). The locations of villages and wards are shown in Figure 1.

\subsection{Stray Dog Count}

The current study was conducted between August 2016 and November 2017. Stray and pet dogs were differentiated according to WSPA guidelines [39]. The purpose of this study was to estimate the size of the stray dog population to inform $A B C$ programs. Therefore, an announcement was made before the stray dog count in the relevant villages and wards about the stray dog counting to encourage people to leash their pet dogs, to avoid over-estimation of the population.

We used a mark-re-sight procedure [40] with modifications [37] to estimate the stray dog populations. In brief, a two-three-person survey team was formed and formally trained to count dogs in all the selected villages and wards. On Day 1, between 5.30-6.30 a.m. in the summer and 6.30-7.30 a.m. in the winter, the team marked stray dogs in the street observed during walks using sprayed water-soluble red paint. Dogs were not physically restrained or captured. In addition, data related to demography, health status (gross examination without restraining for the presence of open wounds, skin disease and skeletal deformity), sex and age (young or adult by observing the external genitalia) were also recorded. The entire village/ward was covered using a pre-determined route which was recorded during the stray dog estimation using Arc GIS explorer10.2.1 software. The area of village/ward covered during the stray dog estimation was also recorded using Arc GIS expo 10.2.1 software. For ease of marking and to make it dog-friendly, we used baits (dog biscuits, dog feed) to feed stray dogs. 


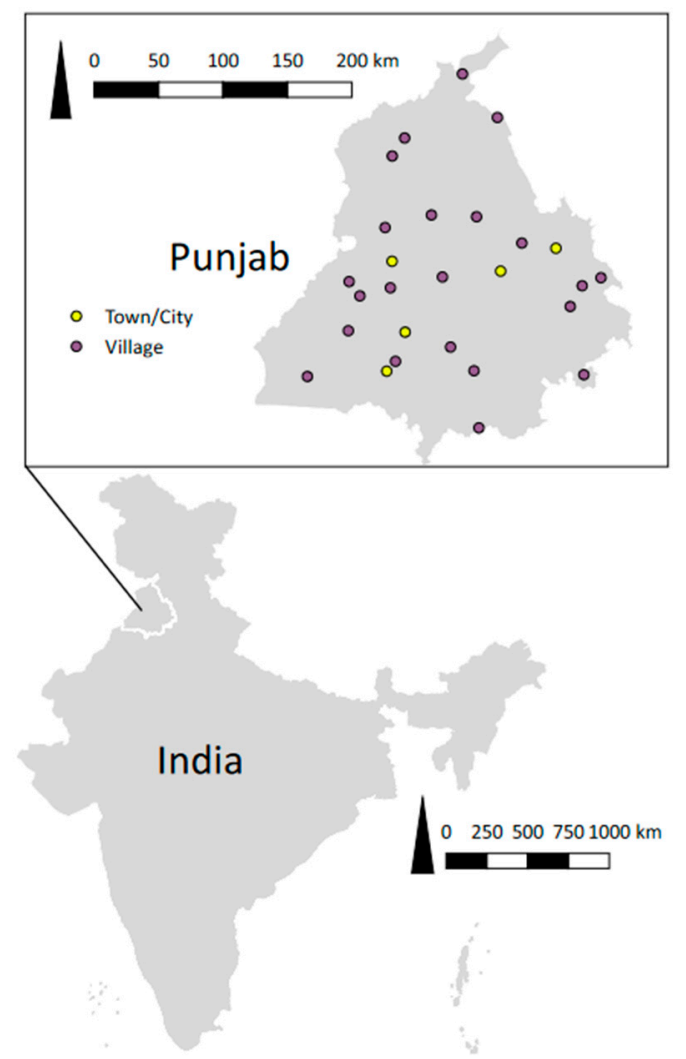

Figure 1. Study area showing 22 villages and 5 cities/towns surveyed in the Punjab state of India to estimate dog populations between August 2016 and November 2017. QGIS 3.6.0 was used to create the figure (qgis.org; accessed on 27 June 2019). The shapefiles are publicly available from diva-gis.org (accessed on 27 June 2019; India and Punjab) or created by the authors (village and cities/towns).

Dogs were photographed if they could not be marked (for example, if they ran away) or had a reddish, black or mixed colour coat. All village or ward areas, including garbage dumps, were systematically searched. The number of dogs marked with colour or which were photographed on Day 1 was recorded and represented ' $n 1$ ' within the mark-re-sight framework.

The Day 1 procedure was repeated on Day 2 in all selected villages and wards. The same start times and routes were followed. The marked dogs encountered on Day 2 were recorded separately. To ensure identification and to avoid double-counting, additional matching with photographs was conducted if required.

\subsection{Population Size Estimates}

\subsubsection{Lincoln-Petersen's Formula with Chapman's Correction}

The total number of dogs counted on Day 2 was designated ' $n 2$ ' and the number of re-sighted (marked or photographically identified) dogs was designated ' $\mathrm{m}$ ' in the mark-re-sight framework. The sizes of the stray dog populations were estimated using the Lincoln-Petersen formula with Chapman's correction [41] according to Equation (1) in which

$$
\begin{gathered}
N=\left[\frac{(n 1+1)(n 2+1)}{m+1}-1\right] \\
\operatorname{var}(N)=\left[\frac{(n 1+1)(n 2+1)(n 1-m)(n 2-m)}{(m+1)^{2}(m+2)}\right] \\
95 \% \text { confidence interval }(C I)=N \pm 1.965 \sqrt{\operatorname{var}(N)}
\end{gathered}
$$


$N$ is the estimate of the total population size, $n 1$ is the total number of dogs marked on Day $1, n 2$ is the total number of dogs sighted on Day 2, and $m$ is the number of marked dogs re-sighted on Day 2. An approximate unbiased variance of $N$ was estimated by using Seber's formula [40] (Equation (2)). The 95\% confidence interval for $N$ was estimated according to Equation (3).

\subsubsection{Recapture Probability}

The recapture probability or the detectability rate $(r)$ was estimated according to Equation (4) in which the number of dogs that were re-sighted on the second day (n2) was divided by the estimated population $(N)$.

$$
r=\frac{n 2}{N}
$$

\subsubsection{SuperDuplicates Method}

The dog counts were also estimated using this method. Population size estimates are based on the presence or absence of each observed dog in repeated samples. The dog population size was estimated using the online tool https://chao.shinyapps.io/ SuperDuplicates / [42] (accessed on 28 October 2021). Data included the total number of observed dogs ('observed species' in this framework), the number of dogs that were sighted only once ('uniques'), and the number of days ('samples').

\subsection{Statistical Analyses}

All statistical analyses were conducted using R statistical program ( $R$ statistical package version 3.4.3, R Development Core Team, http:/ / www.r-project.org; accessed on 28 October 2021).

Descriptive statistics and frequency distributions of gross health examinations, sex and age of the stray dogs were generated for villages and wards. The stray dog population for each village and ward $/ \mathrm{km}^{2}$ was calculated by dividing the stray dog count in the village or ward by the area of the village or ward in $\mathrm{km}^{2}$. Similarly, stray dog population/1000 adult human population (based on the latest voter lists) for each village and ward was estimated by dividing the stray dog count in each village and ward by their respective adult human population.

Stray dog populations (both per $\mathrm{km}^{2}$ and per 1000 adult humans) were compared between villages and wards (urban areas in towns and cities) using linear mixed models with the variable location (village or ward) as a fixed effect and district as a random effect. Similar analyses were conducted using the sex and age groups as fixed effects. Model assumptions were evaluated using residual diagnostics and the outcome variables were logtransformed (if required) to meet the assumptions. Predicted group means and differences between group means were back-transformed for presentation. Note that the predicted means calculated on the log scale become geometric means on back-transformation whereas the differences between the group means become a ratio after back-transformation.

The mean (95\% CI) stray dog population at the state level was estimated separately for rural and urban areas by multiplying (a) the predicted mean (95\% CI) count of the dogs per village or ward with the total number of villages and wards in the state, respectively; (b) the predicted mean (95\% CI) dog count per 1000 adult human population with the total adult human population of the state; and (c) the predicted mean (95\% CI) dog count per $\mathrm{km}^{2}$ residential built-up land area with the total built-up area of the state [43]. We included industrial areas with the urban built-up land area for estimating the urban built-up area. Therefore, a separate analysis was also conducted after excluding the industrial area from the urban built-up area to estimate the number of stray dogs residing in the urban areas. 


\section{Results}

\subsection{Number and Density of Stray Dogs in Village(s)/Ward(s)}

Detailed information on the number of stray dogs estimated using Lincoln-Peterson's formula with Chapman's correction in the selected villages and wards is shown in Table S2. Overall, we recorded 1011 (614 rural and 397 urban) stray dogs on day $1(n 1), 1002$ (606 rural and 396 urban) stray dogs on day 2 ( $n 2)$, and 664 (440 rural and 224 urban) stray dogs were re-sighted $(m)$. The overall detectability rate $(r)$ or recapture probability of stray dogs was $65.7 \%(71.7 \%$ in rural areas compared to $56.5 \%$ in urban areas).

Detailed information on the number of stray dogs estimated in the selected villages and wards using the SuperDuplicates method is shown in Table S3. The incidence data indicated that there are 2076 observed dogs ('observed species' in this framework) and 1349 dogs that were sighted only once ('uniques').

Summary statistics of dog populations per village and ward, $\mathrm{km}^{2}$ and 1000 adult humans estimated using both the methods are presented in Table 1. Dog population estimates were not significantly different between rural and urban areas using Lincoln-Petersen's formula with Chapman's correction or SuperDuplicates method (Table 2). The population of male dogs was significantly higher than that of female dogs and the population of adult dogs was higher than that of young dogs in both Lincoln-Petersen's formula with Chapman's correction and SuperDuplicates estimates (Table 2).

Table 1. Summary statistics of the number of stray dogs in 22 rural and 10 urban areas of the Punjab state of India surveyed between August 2016 and November 2017.

\begin{tabular}{|c|c|c|c|c|c|c|c|c|c|c|c|c|c|}
\hline \multirow{2}{*}{ Count } & \multirow{2}{*}{ Category } & Min & Q1 & Median & Q3 & Max & Mean & Min & Q1 & Median & Q3 & Max & Mean \\
\hline & & \multicolumn{6}{|c|}{ Lincoln-Petersen Formula with Chapman's Correction } & \multicolumn{6}{|c|}{ Super Duplicates Method } \\
\hline \multirow{2}{*}{$\begin{array}{l}\text { Dogs/village } \\
\text { or ward }\end{array}$} & Rural & 13 & 26 & 33 & 50 & 71 & 38 & 24 & 49 & 61 & 97 & 124 & 71 \\
\hline & Urban & 21 & 40 & 65 & 78 & 151 & 68 & 35 & 65 & 112 & 147 & 254 & 116 \\
\hline \multirow{2}{*}{ Dogs $/ \mathrm{km}^{2}$} & Rural & 150 & 238 & 291 & 371 & 506 & 310 & 282 & 438 & 558 & 698 & 952 & 577 \\
\hline & Urban & 59 & 159 & 244 & 340 & 500 & 256 & 101 & 258 & 405 & 647 & 784 & 437 \\
\hline \multirow{2}{*}{$\begin{array}{c}\text { Dogs / } 1000 \\
\text { adult humans }\end{array}$} & Rural & 13 & 22 & 26 & 35 & 43 & 27 & 25 & 41 & 49 & 60 & 79 & 50 \\
\hline & Urban & 9 & 17 & 20 & 37 & 66 & 28 & 16 & 29 & 33 & 60 & 142 & 50 \\
\hline
\end{tabular}

Table 2. Comparison of stray dog populations $\left(/ \mathrm{km}^{2}\right.$ and $/ 1000$ adult human population) between locality, sex and age groups using linear mixed models based on a survey conducted in Punjab, India between August 2016 and November 2017.

\begin{tabular}{|c|c|c|c|c|c|c|c|c|c|}
\hline \multirow{2}{*}{ Count } & \multirow{2}{*}{ Category } & Mean Population & $95 \% \mathrm{CI}$ & Ratio & $p$-Value & Mean Population & $95 \% \mathrm{CI}$ & Ratio & $p$-Value \\
\hline & & \multicolumn{4}{|c|}{ Lincoln-Petersen Formula with Chapman's Correction } & \multicolumn{4}{|c|}{ Super Duplicates Method } \\
\hline \multirow{2}{*}{$\operatorname{Dogs} / \mathrm{km}^{2}$} & Rural & 310 & 262,358 & 1.21 & 0.23 & 577 & 489,666 & 1.32 & 0.08 \\
\hline & Urban & 256 & 185,328 & & & 437 & 306,568 & & \\
\hline \multirow{2}{*}{$\begin{array}{l}\text { Dogs } / 1000 \text { adult } \\
\text { human population }\end{array}$} & Rural & 27 & 22,31 & 1.04 & 0.66 & 51 & 40,59 & 1.16 & 0.34 \\
\hline & Urban & 26 & 18,32 & & & 44 & 31,55 & & \\
\hline \multirow{2}{*}{ Dogs $/ \mathrm{km}^{2}$} & Male & 165 & 142,188 & 1.24 & 0.03 & 305 & 261,349 & 1.21 & 0.03 \\
\hline & Female & 133 & 110,156 & & & 252 & 208,296 & & \\
\hline \multirow{2}{*}{$\begin{array}{l}\text { Dogs/1000 adult } \\
\text { humans }\end{array}$} & Male & 15 & 12,17 & 1.25 & 0.01 & 27 & 22,31 & 1.23 & 0.04 \\
\hline & Female & 12 & 10,13 & & & 22 & 18,25 & & \\
\hline \multirow{2}{*}{ Dogs $/ \mathrm{km}^{2}$} & Young & 69 & 45,93 & 0.31 & $<0.001$ & 133 & 86,180 & 0.32 & $<0.001$ \\
\hline & Adult & 224 & 200,248 & & & 418 & 371,465 & & \\
\hline \multirow{2}{*}{$\begin{array}{c}\text { Dogs } / 1000 \text { adult } \\
\text { humans }\end{array}$} & Young & 6 & 5,7 & 0.29 & 0.001 & 12 & 9,13 & 0.32 & $<0.001$ \\
\hline & Adult & 21 & 17,24 & & & 38 & 31,43 & & \\
\hline
\end{tabular}

\subsection{Stray Dog Count in Punjab}

Detailed information on the number of stray dogs in Punjab estimated from numbers derived using the Lincoln-Peterson formula with Chapman's correction is presented in Table 3. The mean dog population in the state was estimated to be 519,000 (/1000 human population) $-868,000\left(/ \mathrm{km}^{2}\right)$. The population of rural dogs was estimated to be 329,000 (/1000 human population)-576,000 $\left(/ \mathrm{km}^{2}\right)$ and was higher than the estimated population of urban dogs (190,000-292,000). A mean stray dog count of 276,321 (95\% CI: 199,685-354,036) was estimated for the urban areas after excluding the industrial area from 
the urban built-up area. We estimated a human to stray dog ratio of 38:1 and 42:1 in rural and urban areas, respectively.

Table 3. Estimated number of stray dogs (in thousands) in Punjab state of India, extrapolated from a study conducted in 22 villages and 10 wards of the state in 2016-2017.

\begin{tabular}{|c|c|c|c|c|c|c|c|}
\hline \multirow{3}{*}{ Category } & \multirow{3}{*}{ State-Level Data } & \multicolumn{6}{|c|}{ Total Number of Dogs (1000 s) } \\
\hline & & \multicolumn{3}{|c|}{ Lincoln-Petersen Formula with Chapman's Correction } & \multicolumn{3}{|c|}{ Super Duplicates Method } \\
\hline & & Mean & LCL & UCL & Mean & LCL & UCL \\
\hline & Number of villages and wards & & & & & & \\
\hline Rural & 12,581 & 465 & 351 & 551 & 868 & 642 & 1032 \\
\hline Urban & 2496 & 157 & 100 & 206 & 265 & 170 & 205 \\
\hline \multirow[t]{2}{*}{ Total } & 12,581 and 2496 & 622 & 451 & 757 & 1133 & 812 & 1237 \\
\hline & Residential built up area $\left(\mathrm{km}^{2}\right)$ & & & & & & \\
\hline Rural & 1857 & 576 & 487 & 665 & 1071 & 908 & 1237 \\
\hline Urban & 1139 & 292 & 211 & 374 & 498 & 349 & 647 \\
\hline \multirow[t]{2}{*}{ Total } & 2997 & 868 & 698 & 1039 & 1569 & 1257 & 1884 \\
\hline & Adult human population & & & & & & \\
\hline Rural & $12,201,170$ & 329 & 268 & 378 & 622 & 488 & 720 \\
\hline Urban & $7,315,518$ & 190 & 132 & 234 & 322 & 227 & 402 \\
\hline Total & $19,516,688$ & 519 & 400 & 612 & 944 & 715 & 1122 \\
\hline
\end{tabular}

Detailed information on the number of stray dogs in Punjab is using the SuperDuplicates method is also presented in Table 3. The mean dog population in the state was estimated to be 944,000 (/1000 human population)-1,569,000 (/ $\left.\mathrm{km}^{2}\right)$. The population of rural dogs was estimated to be 622,000 (/1000 human population) - 1,071,000 (/ $\left.\mathrm{km}^{2}\right)$ and was higher than the estimated population of urban dogs $(265,000-498,000)$. A mean stray dog count of 471,689 (95\% CI: 330,290-613,087) was estimated for the urban areas after excluding the industrial area from the urban built-up area. We estimated a human to stray dog ratio of 28:1 and 32:1 in rural and urban areas, respectively.

\subsection{Abnormalities Detected in Stray Dogs}

Abnormalities detected in stray dogs are presented in Table 4. During the stray dog count, we estimated gross health abnormalities in 4.4\% (38/845) and 4.7\% (33/701) of the dogs residing in rural and urban areas, respectively (chi square $=0.35, p=0.85$ ). Gross health abnormalities such as wound (chi square $=0.12, p=0.72$ ), skin diseases (chi square $=0.08$, $p=0.77$ ) and emaciation (chi square $=0.007, p=0.95$ ) did not differ significantly between the rural and urban areas.

Table 4. Frequency table for abnormalities recorded in stray dogs residing in rural $(n=845)$ and urban $(n=701)$ areas in Punjab during a survey conducted 2016-2017.

\begin{tabular}{ccc}
\hline Type of Abnormality & Frequency & Relative Frequency (\%) \\
\hline Rural areas & & \\
\hline Wounds & 7 & 0.82 \\
Skin diseases (scabies/mange/inflammation) & 11 & 1.30 \\
Fractures & 2 & 0.23 \\
Hind-limb paralysis & 3 & 0.35 \\
Emaciation & 14 & 1.65 \\
Mandibular deformity & 1 & 0.11 \\
Gross health abnormalities & 38 & 4.40 \\
\hline Urban areas & & 0.99 \\
Wounds & 7 & 1.14 \\
Skin diseases (scabies/mange/inflammation) & 8 & 0.28 \\
Fractures & 2 & 0.57 \\
Hind-limb paralysis & 4 & 1.71 \\
Emaciation & 12 & 4.70 \\
\hline
\end{tabular}




\section{Discussion}

As far as we are aware, this is the first systematic estimation of the stray dog population in Punjab. According to 2012 official data, there were estimated to be 305,482 stray dogs in Punjab [44]. However, we estimated the stray population to be 519,000 to $1,569,000$ using mark-re-sight and the Superduplicates method, which is much higher than the official estimates. Mark-re-sight is considered a practical way to accurately estimate the number and distribution of a stray dog population if the assumption of a closed population is fulfilled $[40,45]$. In the present investigation, marking and subsequent counting events were completed within two days and thus the assumption of a closed population was likely valid because the period between the counting events was very short. Recent studies indicate that the SuperDuplicates method is also useful to estimate dog counts, particularly for two sample surveys conducted on consecutive days [36]. The large difference between our estimate and the official estimate could be explained by the animal husbandry department having estimated the stray dog population size in 2011; there might have been a substantial increase in the stray dog population since then due to the lack of effective stray dog control programs. Differences in the methods used may also be responsible for differences in stray dog estimations. This is consistent with the findings of researchers in other areas [46].

Our estimate of a higher male to female dog population ratio is similar to the findings of other national and international studies $[27,37,47,48]$. Whilst this might be due to methodology differences or measurement error, many factors that influence higher male survivability or higher mortality in female dogs favour a high population of male dogs. Populations with unequal sex ratios have a lower reproduction potential compared to equal sex ratio populations [49]. The sex ratio of the owned dog population might be responsible for this phenomenon. It has been reported that owners and farming communities prefer male dogs due to guarding requirements, reduced nuisance behaviour during oestrus, and avoiding unwanted puppies when compared to adult females [50,51]. However, this needs to be further investigated.

The higher adult population estimated in the current study is consistent with many other international dog count estimates $[27,48]$. High early life mortality has been reported among free-ranging puppies from India [52], but as far as we are aware, the life expectancy of stray dogs in India is unknown. Whilst the average life expectancy among companion dogs can be relatively long-for example, it has been reported to be 13.7 years in Japan [53], we expect it to be much shorter in free-roaming dogs. Further studies need to be conducted to understand adult-juvenile dog ratios in the state.

We extrapolated the dog population to the state level based on the number of villages and wards, residential (built-up) areas and the adult human population residing in the surveyed areas. The dog population estimates were highest based on the built-up area and were lowest based on the adult human population. It needs to be ascertained which method provides a better estimate because a "gold standard" was not available in the current study. We are not aware of any previous studies using these methods to extrapolate dog population data. Further investigations are required to evaluate the accuracy of these methods. The estimates using a mark-re-sight method to estimate the dog population size observed a re-sight probability of stray dogs of $66 \%$ (rural $72 \%$ and urban $56 \%$ ). Similar resight (recapture) probabilities between 61\% and 63\% have been estimated in some previous studies [37,54], whereas a lower probability of $46-49 \%$ has also been reported [38].

We estimated a human to stray dog ratio of 28-38:1 and 32-42:1 in rural and urban areas, respectively. This is higher than the World Health Organizations average estimate of 10 people/dog. Human to stray dog ratios have been reported to be 15:1 in Bhutan [38], 4.7:1 in Kathmandu, Nepal [55], 5.2:1 in Shimotsui, Japan, 23:1 in Timor Leste [54] and 828:1 and 120:1 in Bangladesh [37,50]. The human-stray dog ratio estimated in the current study is lower than those reported in Bangladesh but higher than Bhutan, Nepal and Japan, which might be due to socio-cultural and human population density differences in different countries. For example, the Bangladeshi study was conducted in Dhaka [37], one of the most densely populated cities in the world. 
We estimated the dog density in rural and urban areas to be $310-577$ and $256-437 / \mathrm{km}^{2}$ built-up area, respectively. A range of dog densities have been reported in previous studies: 185 free-ranging dogs $/ \mathrm{km}^{2}$ from West Bengal, India [47], 57 free-ranging dogs $/ \mathrm{km}^{2}$ in Mumbai, India [28], 225 stray dogs $/ \mathrm{km}^{2}$ in Shimotsui, Japan [55], 2930 stray dogs $/ \mathrm{km}^{2}$ in Kathmandu, Nepal [55], 52 dogs $/ \mathrm{km}^{2}$ [37] and $14 \mathrm{dogs} / \mathrm{km}^{2}$ [50] in Bangladesh. These densities have been estimated from small areas, and therefore, might not be representative of the country or state level. Practices such as waste disposal that affect the availability of food, as well as space, can influence the stray dog populations within these areas.

This study had several limitations. We only surveyed 22 villages and 10 wards of Punjab. Stray dog estimation from additional villages and wards could have improved the precision of our estimates. The target population was stray dogs to inform dog control programs. We faced a problem of dogs running away before being marked. Our solution was to use food baits to facilitate marking Day 1 sighted dogs. In a vaccination program in Western India, the use of a food bait enabled access to $80 \%$ of the sighted dogs in a rabies vaccination program [56]. Further, we believed that food baits were essential to avoid dog bites to researchers. However, the effect of food baits on the overall dog count needs to be considered. Both positive (food baits) and negative (marking) reinforcements could have influenced dog behaviour and the probability of being re-sighted on Day 2, affecting the recapture counts. If the baiting on Day 1 artificially inflated the number of dogs re-sighted on Day 2 (because dogs returned for food), this would have resulted in an underestimate of dog numbers. If the opposite happened and these dogs actively avoided the counters (for fear of being marked again) on Day 2, then there would be an overestimation of dog numbers. We believe that the combination of these two potential errors is likely to have resulted in no substantial bias. The influence of physical marking of street dogs during counts has not been previously considered [57]. An alternative is to use photographs only, for example, using an iPad or tablet [58]. The mean dog counts per village/ward were higher using the SuperDuplicates method compared to Lincoln-Petersen's formula with Chapman's correction. Further, we only used two surveys to achieve this estimate. We recommend studies in the future to refine these estimates.

Although we took the utmost care in estimating only the stray dog population, some proportion of free-roaming, owned dogs could have been counted as stray dogs. The stray dogs were not captured and conditions such as tick infestation and lactation status could not be estimated. Moreover, dogs were not physically restrained or captured for gross health examinations. Therefore, the gross-health abnormalities are likely to be under-reported. The number of lactating females might serve as an indicator of the population turnover of stray dogs. We purposively selected villages and wards and believe that random selection at the village and ward level is unnecessary because villages and wards in Punjab are very homogenous with respect to socio-economic indicators and other factors such as human population density. However, the presence of waste dumps, natural carcass disposal sites and restaurants in some of the selected areas might have biased the results. In addition, although we took care to count re-sighted dogs through marking and photographic records, a small mismatch error was possible.

We used a recommended mark-re-sight approach and GPS-based measurements of residential areas to improve the accuracy of the dog population estimates in Punjab, India.

Overall, we estimated that there are 519 to 1569 thousand stray dogs with a higher number residing in rural areas compared to urban areas, more male than female dogs, and more adult than young stray dogs in Punjab. We also estimated the burden of a range of health abnormalities in this population.

\section{Conclusions}

The estimated stray dog numbers pose a potential public health hazard in Punjab. Our estimates are higher than previous estimates and therefore, the potential impact and the impact of stray-dog population control requires assessment. The estimated stray dog numbers can be used to guide the development of a dog population control program in 
Punjab, especially if detailed information about resources (including costs) and logistics required can be included.

Supplementary Materials: The following supporting information can be downloaded at: https: / / www.mdpi.com/article/10.3390/vetsci9020075/s1, Table S1: The adult human population (Census India 2011) and the residential area of selected villages and wards included in a survey to determine the dog population of the Punjab state of India; Table S2: Total number of stray dogs estimated in different village(s)/ward(s) in Punjab state of India (using Lincoln-Petersen's formula with Chapman's correction); Table S3: Total number of stray dogs estimated in different village(s)/ward(s) in Punjab state of India (using SuperDuplicates method).

Author Contributions: Conceptualization, B.B.S. and N.K.D.; methodology, B.B.S. and N.K.D.; formal analysis, B.B.S. and N.K.D.; investigation, G.S.G.; data curation, G.S.G.; writing-original draft preparation, G.S.G.; writing-review and editing, B.B.S., N.K.D., R.S.A., M.P.W. and V.J.B.; supervision, N.K.D., M.P.W. and V.J.B.; project administration, B.B.S. All authors have read and agreed to the published version of the manuscript.

Funding: This research received no external funding.

Institutional Review Board Statement: The animal care and use protocol adhered to the guidelines of the Committee for the Purpose of Control and Supervision of Experiments on Animals (CPCSEA), Government of India. The permission from Institutional Animal Ethics Committee, GADVASU, Ludhiana was not undertaken as no experimental animals or intervention procedures were involved in this study (Not applicable).

Informed Consent Statement: Not applicable.

Data Availability Statement: The data has been supplied as a Supplementary Materials along with the manuscript.

Acknowledgments: The help obtained from field veterinarians and village/ward heads is kindly acknowledged. The publication funding received from Michael P Ward, Sydney School of Veterinary Science, The University of Sydney, Australia is thankfully acknowledged.

Conflicts of Interest: The authors declare no conflict of interest.

\section{References}

1. Larson, G.; Karlsson, E.K.; Perri, A.; Webster, M.T.; Ho, S.Y.; Peters, J.; Stahl, P.W.; Piper, P.J.; Lingaas, F.; Fredholm, M.; et al. Rethinking dog domestication by integrating genetics, archeology and biogeography. Proc. Natl. Acad. Sci. USA 2012, 109, 8878-8883. [CrossRef] [PubMed]

2. McNicholas, J.; Gilbey, A.; Rennie, A.; Ahmedzai, S.; Dono, J.; Ormerod, E. Pet ownership and human health: A brief review of evidence and issues. Br. Med. J. 2005, 331, 1252-1254. [CrossRef] [PubMed]

3. Christian, H.E.; Westgarth, C.; Bauman, A.; Richards, E.A.; Rhodes, R.; Evenson, K.R. Dog ownership and physical activity: A review of the evidence. J. Phys. Act. Health 2013, 10, 750-759. [CrossRef] [PubMed]

4. Muldoon, A.L.; Kuhns, L.M.; Supple, J.; Jacobson, K.C.; Garofalo, R.A. Web-Based Study of Dog Ownership and Depression Among People Living With HIV. JMIR Ment. Health 2017, 4, e53. [CrossRef]

5. Headey, B.; Krause, P. Health benefits and potential budget savings due to pets. Australian and German survey results. Aust. Soc. Monit. 1999, 2, 4-6.

6. Allen, K.; Shykoff, B.E.; Izzo, J.L.J. Pet ownership, but not ace inhibitor therapy, blunts home blood pressure responses to mental stress. Hypertension 2001, 38, 815-820. [CrossRef]

7. Kingwell, B.A.; Lomdahl, A.; Anderson, W.P. Presence of a pet dog and human cardiovascular responses to mild mental stress. Clin. Auton. Res. 2001, 11,313-317. [CrossRef]

8. Shimozako, A.J.; Cout, E.B., Jr. Photographic Capture-Recapture for Estimation of Stray Dog Population; Verlag: Saarbrucken, Germany, 2008.

9. Alves, A.J.S.; Guiloux, A.G.A.; Zetun, C.B.; Polo, G.; Braga, G.B.; Panachão, L.I.; Santos, O.; Dias, R.A. Abandonment of dogs in Latin America: Review of literature. Contin. Educ. J. Vet. Med. Zootech. CRMV-SP 2013, 11, 32-39.

10. Miklosi, A. Dog Behaviour, Evolution and Cognition; Oxford University Press: Oxford, UK, 2008; p. 25.

11. Sarcase, C. Guide du Chien Citadin; Atlas: Paris, France, 1985.

12. Overgaauw, P.A.; Van-Knapen, F. Veterinary and public health aspects of Toxocara spp. Vet. Parasitol. 2013, 193, 398-403. [CrossRef]

13. Da Silva, A.M. Human echinococcosis: A neglected disease. Gastroenterol. Res. Pract. 2010, 2010, 583297. [CrossRef] 
14. Macpherson, C.N.L.; Torgerson, P.R. Dogs and Cestode Zoonoses. Dogs, Zoonoses and Public Health; Macpherson, C.N.L., Meslin, F.X., Wandeler, A.I., Eds.; CAB International: Wallingford, UK, 2013.

15. Beck, A.M. The Ecology of Stray Dogs: A Study of Free-Ranging Urban Animals, 1st ed.; NotaBell Books; Purdue University Press: West Lafayette, IN, USA, 2002; pp. 1-98.

16. Ugbomoiko, U.S.; Ariza, L.; Heukelbach, J. Parasites of importance for human health in Nigerian dogs: High prevalence and limited knowledge of pet owners. BMC Vet. Res. 2008, 4, 49. [CrossRef] [PubMed]

17. Tenzin, D.N.K.; Gyeltshen, T.; Firestone, S.; Zangmo, C.; Dema, C.; Gyeltshen, R.; Ward, M.P. Dog bites in humans and estimating human rabies mortality in rabies endemic areas of Bhutan. PLoS Negl. Trop. Dis. 2011, 5, e1391. [CrossRef]

18. Lunney, M.; Jones, A.; Stiles, E.; Waltner-Toews, D. Assessing human-dog conflicts in Todos Santos, Guatemala: Bite incidences and public perception. Prev. Vet. Med. 2011, 102, 315-320. [CrossRef]

19. Høgåsen, H.R.; Er, C.; Di Nardo, A.; Dalla-Villa, P. Free-roaming dog populations: A cost-benefit model for different management options, applied to Abruzzo, Italy. Prev. Vet. Med. 2013, 112, 401-413. [CrossRef]

20. Webster, D. The Economic Impact of Stray Cats and Dogs at Tourist Destinations on the Tourism Industry; Diana Webster and Candi International: Ridgewood, NJ, USA, 2013; pp. 1-19.

21. Amaku, M.; Dias, R.A.; Ferreira, F. Dynamics and Control of Stray Dog Populations. Math. Popul. Stud. 2010, 17, 69-78. [CrossRef]

22. Garcia, R.C.M.; Calderón, N.; Ferreira, F. Consolidation of international guidelines for management of canine populations in urban areas and proposed indicators for their management. Rev. Panam. Salud Publica 2012, 32, 140-144. [CrossRef]

23. Suraweera, W.; Morris, S.K.; Kumar, R.; Warrell, D.A.; Warrell, M.J.; Jha, P. Deaths from symptomatically identifiable furious rabies in India: A nationally representative mortality survey. PLoS Negl. Trop. Dis. 2012, 6, e1847. [CrossRef] [PubMed]

24. Menezes, R. Rabies in India. CMAJ 2008, 178, 564-566. [CrossRef]

25. Sharma, R.; Singh, B.B.; Gill, J.P.S.; Jenkins, E.; Singh, B. Canine parasitic zoonoses in India: Status and issues. Rev. Sci. Tech. 2017, 36, 817-830. [CrossRef] [PubMed]

26. Hiby, L.R.; Reece, J.F.; Wright, R.; Jaisinghani, R.; Singh, B.; Hiby, E.F. A mark-resight survey method to estimate the roaming dog population in three cities in Rajasthan, India. BMC Vet. Res. 2011, 7, 46. [CrossRef] [PubMed]

27. Totton, S.C.; Wandeler, A.I.; Zinsstag, J.; Bauch, C.T.; Ribble, C.S.; Rosatte, R.C.; McEwen, S.A. Stray dog population demographics in Jodhpur, India following a population control/rabies vaccination program. Prev. Vet. Med. 2010, 97, 51-57. [CrossRef] [PubMed]

28. Punjabi, G.A.; Athreya, V.; Linnell, J.D.C. Using natural marks to estimate free-ranging dog Canis familiaris abundance in a MARK-RESIGHT framework in suburban Mumbai, India. Trop. Conserv. Sci. 2012, 5, 510-520. [CrossRef]

29. Butcher, R. Stray dogs-A worldwide problem. J. Small Anim. Pract. 1999, 40, 458-459. [PubMed]

30. Reece, J.F.; Chawla, S.K. Control of rabies in Jaipur, India, by the sterilisation and vaccination of neighbourhood dogs. Vet. Rec. 2006, 159, 379-383. [CrossRef]

31. Reece, J.F.; Chawla, S.K.; Hiby, E.F.; Hiby, L.A. Fecundity and longevity of free- roaming dogs in Jaipur, India. BMC Vet. Res. 2008, 4, 6. [CrossRef] [PubMed]

32. Totton, S.C.; Wandeler, A.I.; Ribble, C.S.; Rosatte, R.C.; McEwen, S.A. Stray dog population health in Jodhpur, India in the wake of an animal birth control (ABC) program. Prev. Vet. Med. 2011, 98, 215-220. [CrossRef]

33. BAHS Basic Animal Husbandry and Fisheries Statistics. 19th Livestock Census; Department of Animal Husbandry, Dairying and Fisheries, Ministry of agriculture, Government of India: New Delhi, India, 2012.

34. World Health Organization. World Health Organization/World Society for the Protection of Animals. Guidelines for Dog Population Management; World Organization for Animal Health: Geneva, Switzerland, 1990.

35. OIE World Organisation for Animal Health. OIE Terrestrial Animal Health Code, Chapter 7.7, Stray Dog Population Control. 2010. Available online: http://web.oie.int/eng/normes/mcode/en_chapitre_1.7.7.htm (accessed on 20 January 2018).

36. Tiwari, H.K.; Vanak, A.T.; O'Dea, M.; Gogoi-Tiwari, J.; Robertson, I.D. A Comparative Study of Enumeration Techniques for Free-Roaming Dogs in Rural Baramati, District Pune, India. Front. Vet. Sci. 2018, 5, 104. [CrossRef] [PubMed]

37. Tenzin, T.; Ahmed, R.; Debnath, N.C.; Ahmed, G.; Yamage, M. Free-roaming dog population estimation and status of the dog population management and rabies control program in Dhaka city, Bangladesh. PLoS Negl. Trop. Dis. 2015, 9, e0003784. [CrossRef]

38. Rinzin, K.; Tenzin, T.; Robertson, I. Size and demography pattern of the domestic dog population in Bhutan: Implications for dog population management and disease control. Prev. Vet. Med. 2016, 126, 39-47. [CrossRef]

39. World Society for the Protection of Animals. Surveying Roaming Dog Populations: Guidelines on Methodology. Companion E Working Animals Unit; World Society for the Protection of Animals: London, UK, 2009; p. 89.

40. Seber, G.A.F. The effects of trap response on tag recapture estimates. Biometrics 1970, 26, 13-22. [CrossRef]

41. Chapman, D.G. Some Properties of the Hypergeometric Distribution with Applications to Zoological Sample Censuses; University of California Press: Berkeley, CA, USA, 1951; pp. 131-160.

42. Chao, A.; Colwell, R.K.; Chiu, C.H.; Townsend, D. Seen once or more than once: Applying Good-Turing theory to estimate species richness using only unique observations and a species list. Methods Ecol. Evol. 2017, 8, 1221-1232. [CrossRef]

43. National Institute of Disaster Management. National Disaster Risk Portal, Punjab; National Institute of Disaster Management: New Delhi, India, 2012; pp. 1-38. 
44. Department of Animal Husbandry Punjab. Livestock Population Data of Punjab According to 19th Indian Livestock Census 2012, Conducted by Department of Animal Husbandry Punjab. 2012. Available online: http:/ / www.husbandrypunjab.org/livestock. html (accessed on 17 June 2017).

45. Cooch, E.G.; White, G.C. Program MARK: A Gentle Introduction, 13th ed.; Colorado State University: Collins, CO, USA, 2014.

46. Davis, J.; Menon, N. A survey of human and animal casualties resulting from bites of stray dogs in the municipal area in Palakkad district, Kerala. Int. J. Infect. Dis. 2016, 45, 466-467. [CrossRef]

47. Pal, S.K. Population ecology of free-ranging urban dogs in West Bengal, India. Acta Theriol. 2001, 46, 69-78. [CrossRef]

48. Mustiana, A.; Toribio, J.A.; Abdurrahman, M.; Suadnya, I.W.; Hernandez-Jover, M.; Putra, A.A.G.; Ward, M.P. Owned and unowned dog population estimation, dog management and dog bites to inform rabies prevention and response on Lombok Island, Indonesia. PLoS ONE 2015, 10, e0124092. [CrossRef]

49. Shuster, S.M.; Wade, M.J. Mating Systems and Strategies; Princeton University Press: Princeton, NJ, USA, $2003 ;$ p. 533.

50. Hossain, M.; Ahmed, K.; Marma, A.S.P.; Hossain, S.; Ali, M.A.; Shamsuzzaman, A.K.; Nishizono, A. A survey of the dog population in rural Bangladesh. Prev. Vet. Med. 2013, 111, 134-138. [CrossRef] [PubMed]

51. Margawani, K.; Robertson, I. A survey of urban pet ownership in Bali. Vet. Rec. 1995, 137, 486-488. [CrossRef]

52. Paul, M.; Majumder, S.S.; Sau, S.; Nandi, A.K.; Bhadra, A. High early life mortality in free-ranging dogs is largely influenced by humans. Sci. Rep. 2016, 6, 19641. [CrossRef] [PubMed]

53. Inoue, M.; Kwan, N.C.L.; Sugiura, K. Estimating the life expectancy of companion dogs in Japan using pet cemetery data. J. Vet. Med. Sci. 2018, 80, 1153-1158. [CrossRef] [PubMed]

54. Amaral, A.C.; Ward, M.P.; da Costa Freitas, J. Estimation of roaming dog populations in Timor Leste. Prev. Vet. Med. 2014, 113, 608-613. [CrossRef] [PubMed]

55. Kato, M.; Yamamoto, H.; Inukai, Y.; Kira, S. Survey of the stray dog population and the health education program on the prevention of dog bites and dog-acquired infections: A comparative study in Nepal and Okayama Prefecture, Japan. Acta Med. Okayama 2003, 57, 261-266.

56. Gibson, A.D.; Yale, G.; Vos, A.; Corfmat, J.; Otter, I.; King, A.; Wallace, R.; Gamble, L.; Handel, I.; Mellanby, R.; et al. Oral bait handout as a method to access roaming dogs for rabies vaccination in Goa, India: A proof of principle study. Vaccine 2019, 1, 100015. [CrossRef] [PubMed]

57. Tenzin, T.; McKenzie, J.S.; Vanderstichel, R.; Rai, B.D.; Rinzin, K.; Tshering, Y.; Pem, R.; Tshering, C.; Dahal, N.; Dukpa, K.; et al Comparison of mark-resight methods to estimate abundance and rabies vaccination coverage of free-roaming dogs in two urban areas of south Bhutan. Prev. Vet. Med. 2015, 118, 436-448. [CrossRef] [PubMed]

58. Hudson, E.G.; Brookes, V.J.; Ward, M.P. Demographic studies of dogs in the Northern Peninsula Area, Australia to inform population and disease management strategies. Aust. Vet. J. 2018, 96, 487-494. [CrossRef] 